IZA DP No. 5114

Bringing Financial Literacy and Education to Low and Middle Income Countries: The Need to Review, Adjust, and Extend Current Wisdom

Robert Holzmann

August 2010 


\title{
Bringing Financial Literacy and Education to Low and Middle Income Countries: The Need to Review, Adjust, and Extend Current Wisdom
}

\author{
Robert Holzmann \\ World Bank, CES and IZA
}

Discussion Paper No. 5114

August 2010

IZA

P.O. Box 7240

53072 Bonn

Germany

Phone: $+49-228-3894-0$

Fax: +49-228-3894-180

E-mail: iza@iza.org

Any opinions expressed here are those of the author(s) and not those of IZA. Research published in this series may include views on policy, but the institute itself takes no institutional policy positions.

The Institute for the Study of Labor (IZA) in Bonn is a local and virtual international research center and a place of communication between science, politics and business. IZA is an independent nonprofit organization supported by Deutsche Post Foundation. The center is associated with the University of Bonn and offers a stimulating research environment through its international network, workshops and conferences, data service, project support, research visits and doctoral program. IZA engages in (i) original and internationally competitive research in all fields of labor economics, (ii) development of policy concepts, and (iii) dissemination of research results and concepts to the interested public.

IZA Discussion Papers often represent preliminary work and are circulated to encourage discussion. Citation of such a paper should account for its provisional character. A revised version may be available directly from the author. 


\begin{abstract}
Bringing Financial Literacy and Education to Low and Middle Income Countries: The Need to Review, Adjust, and Extend Current Wisdom ${ }^{*}$

This paper presents a World Bank led and Russia trust fund financed work program to measure financial capability and the effectiveness of financial education in low and middle income countries. The two activities and their staging have been motivated by the lessons of high-income countries with financial literacy programs and the deviating characteristics of low and middle income countries. While progress has been made in high-income countries to measure financial capability, there is little robust empirical evidence that financial education can improve it. While applying the financial capability concept in low and middle-income countries looks promising it will need to be adjusted to their characteristic and supported by innovative interventions and rigorous impact evaluation to improve it.
\end{abstract}

JEL Classification: $\quad$ C93, G29, I122

Keywords: financial literacy, financial capability, financial education, impact evaluation

Corresponding author:

Robert Holzmann

Marseille Center for Mediterranean Integration

World Bank

Villa Valmer, 271 Corniche Kennedy

F-13007 Marseilles

France

Email: rholzmann@worldbank.org

\footnotetext{
* Revised and extended paper prepared for the Conference on Financial Literacy: Implications for Retirement Security and the Financial Market Place, The Wharton School of the University of Pennsylvania, April 29-30, 2010. A shortened version will be published in the conference volume. The paper has profited from comments by the conference participants and very valuable comments and suggestions by Richard Hinz, Elaine Kempson, Andrei Markov, Florentina Mulaj, Valeria Perotti and Yann Puget. The paper presents his own views that do not necessarily reflect the position and views of the organizations he is associated with.
} 


\section{Introduction}

The last 10 years or so have experienced strong and rising interest in financial literacy and in public and private measures to improve it. While this interest has initially been concentrated in high-income countries the enthusiasm has expanded to the poorer part of the world. The common theme across all countries is the assessment that the level of understanding of financial issues by individuals is too low, with negative consequences for individuals (such as undersaving or wrong product choices) and the economy (such as less efficient financial markets). Providing financial education is seen as the key intervention that reduces ignorance and improves outcomes. A few rich countries have established a comprehensive national financial literacy strategy and many others are thinking about. Many poorer countries want to do so likewise and are looking for guidance and support. While substantial progress has been in bringing countries and key country actors together to exchange information and experiences on concepts and practices, there has been less progress on the conceptual and empirical side in highincome countries to guide convincingly low and middle income countries in their ambitions. Conceptual uncertainly concerns the objectives, definition and measurement of financial literacy; empirical uncertainty concerns the effectiveness of financial education compared to other interventions to improve outcomes. And even if more conceptual and empirical certainty were to exist in high income countries, the translation into a low- and middle-income environment may be far from straightforward.

Conceptual and empirical uncertainty is normal for a new topic and typical for a pre-paradigm phase in any new discipline, in particular one that covers aspects from many different disciplines. To reduce this uncertainty and to move toward a broadly shared conceptual framework calls, inter alia, for analytical rigor, empirical testing, and high-quality knowledge exchange with the occasional strong academic dispute that should be embraced and not avoided. Translating a not yet fully established framework from high to low and middle income countries calls, in addition, for careful review and adjustment of existing approaches to the specific circumstances in the latter countries.

The World Bank's interest in the topic is closely linked with her development mandate and the critical role of functioning financial intermediation for development along economic and social dimensions. Successful intermediation requires a well developed financial sector, sound regulation, and a financially capable population. Then such intermediation will be able to deliver on critical economic aspects such as inter-temporal exchange and risk diversification as well as social policy aspects and the management of income and risks across the individual life-cycle. This is important for all levels of development but the content and measurement of financial capability and the interventions to achieve it are likely to differ across the development stage.

This paper presents the approach for supporting financial literacy and education in low- and middle income countries that is currently under implementation by the World Bank under a trust 
fund financed by the Government of the Russian Federation. The World Bank-led activities focus on the development of methodologies and operational instruments for the measurement of financial literacy (actual capabilities) and of the effectiveness of financial education in low and middle income countries. It will draw on the parallel stock-taking activities by the OECD in their member countries that also profit from this trust fund. The disseminated results of both activities should help countries to better design national strategies and interventions.

To motivate the selected approach and planned implementation of the World Bank-led work program the paper starts out with some conceptual considerations derived from the financial literacy and education (FL\&E) discourse in high-income countries (Section 2). This is followed by outlining the special circumstances to consider when translating concepts and approaches to a low- and middle income environment (Section 3). Section 4 will then present the selected approach as well as programmed implementation for low and middle income countries, i.e. the focus of work program of the World Bank. The paper ends with the conclusions drawn in Section 5 .

\section{Lessons and Issues from High-Income Countries (HICs)}

Over the last decade major initiatives on financial literacy and education have been undertaken by a number of high-income countries, in particular in the Anglo-Saxon world, and main progress has been made in sharing that experience under the leadership of the OECD. Agencies created in New Zealand (Retirement Commission, 1995), United Kingdom (Financial Service Authority, 2000), Canada (Financial Consumer Agency, 2001), USA (Financial Literacy and Education Commission, 2003), and Australia (Financial Literacy Foundation, 2005, and since transferred to the Australian Securities and Investments Commission) have taken the lead on financial literacy issues and their web-site provide a wealth of national and international information, including on innovative studies and tools. Yet, despite all these efforts only a few countries have a consistent approach in this new policy area, such as the UK. The OECD's Financial Education project of 2003 started an international assessment how much people know and the 2005 study on Improving Financial Literacy: Analysis of Issues and Policies (OECD 2005) was the first stock taking at international level. And in 2008 OECD created the International Network on Financial Education and the International Gateway for Financial Education as international clearinghouse on financial education ${ }^{1}$. In parallel the academic literature on financial literacy and financial education has increased impressively as any websearch will document.

Reviewing this policy and academic discourse on financial literacy and education for the purpose of application in low and middle income countries a number of lessons and issues stick out.

\footnotetext{
${ }^{1}$ See OECD website for events and documents: http://www.oecd.org/topic [Financial Markets/Financial Education]
} 


\section{(i) Broadening the Concept of Financial Literacy and Measurement}

While the notion of financial literacy is still used in many countries and studies as issue of concern and analysis, its content has moved from financial knowledge and understanding to include financial skills and competences, attitudes and behavior. To signal this broader concept the UK has coined the notion of financial capability that is increasingly used by other countries and in studies ${ }^{2}$. This change in content and definition is important as it has a major bearing on how the objectives are defined and measured and the choice of interventions how to improve them. And there seems to be consensus nowadays that the broader concept is more relevant for the issue at hand. But how best to define, measure, and influence it is still a moving target.

The concept of financial capability proposes that at the end of the day financially capable individuals should demonstrate a desired financial behavior such as drawing-up a budget, and planning and saving for old age. To move to such a stage it is conceptualized by functional components and the move overtime from knowledge to skills to attitudes to behavior (see, e.g. Kempson 2008). Knowledge would include the purpose of saving and its instruments, skills the capacity making a saving plan, attitude the willingness to save ahead, and behavior to put aside the saving. In this conceptualization information and cognitive understanding is the basis of the ultimate desired financial behavior. This information-based cognitive route is also the underlying concept of much of the financial education. And it is also the content of most academic studies that take course participation (as input) to measure the impact on cognitive skills (as intermediate outputs) or actual behavior (as outcome). But this value chain may neither be needed to achieve outcomes nor may it work they way it is conceptualized (discussed below).

But independent of the type of interventions that may trigger financial capability, the issue of how best to define the content domains of financial capability remains. And this should best start out with a working definition of financial capability: "A financially capable person is one who has the knowledge, skills and confidence to be aware of financial opportunities, to know where to go for help, to make informed choices, and to take effective action to improve his or her financial well-being while an enabling environment for financial capability building would promote the acquisition of those skills” (Kempson, 2008).

To operationalize the financial capability concept FSA proposes five content domains that have been the basis of the UK national financial capability survey 2005 (see FSA, 2005, and FSA, 2006a-c):

- Keeping track

- Making ends meet

- Planning ahead

- Choosing products, and

- Staying informed

\footnotetext{
${ }^{2}$ In this paper we use financial literacy interchangeably with financial capability and have thereby the broader definition in mind. If financial literacy is meant in the narrow sense of knowledge and skills, it will be highlighted.
} 
This approach that was developed bottom-up through focus groups and exploratory studies seems to emerge as the consensus' approach how to measure financial capability and to identify capability gaps and target groups. It has been applied with adjustments in Ireland (2008) and Canada (2010), and has informed surveys undertaken in the Netherlands, Australia and the United States. Other countries are thinking about its application. Hence it has the making of becoming the nucleus for an international methodology to measure financial literacy/capability across time and space.

While the content domains seem to have universal appeal and application, the key challenge is to translate them into questions and coding that take account of national and local circumstances and, particularly, the situations of people on low incomes in low- or middle-income countries. Ideally questions and scores should be universal but country and context-specific adjustments in questions and/or coding are likely to be required. To do so well will need substantial preparatory work and coordination across countries to achieve comparable results.

\section{(ii) Establishing an Evaluation Results Framework and Testing for Financial Education Programs}

The accelerated country work and intensive exchange across countries have favored the understanding of the importance of a full results framework that details the answers to the key questions: Why and what, for whom, and how ${ }^{3}$. Ideally, such a framework provides the detailed link between national as well as individual program objectives, inputs, delivery, outputs, outcomes, and impacts. To establish and implement such a framework requires (a) a clear formulation of the objectives that a national strategy and the individual components want to achieve; (b) a clear presentation of the hypotheses how proposed interventions (type of intervention and delivery mode) are conjectured to influence outputs and outcomes; and (c) an ex-ante developed approach for the qualitative and quantitative monitoring and (impact) evaluation. In the practical implementation key elements of such a framework are still missing.

The objectives for enhanced financial understanding (literacy/capability) are relatively well articulated and range from increased supply and complexity of financial markets instruments to the need of individuals to take better care of their own against the background of perceived low levels of financial literacy and the consequences for individuals and society (see, e.g. Orton 2007). However, in order to make these objectives operational it requires a much more detailed breakdown and appropriate indicator' selection for which there is currently no broad consensus as this is work in development. More specific objectives reflect often country specific concerns that change and differ across time and space. Last but not least, while specific objectives and indicators are much more easily established for individual programs, bringing them together in a consistent national strategy is still art and little science.

\footnotetext{
${ }^{3}$ For elements of such a framework see Mircofinance Opportunities (2006 and 2008), Atkinson and Kempson (2008), Kempson (2008), O’Connell (2009), and Mundy (2009).
} 
The link between objectives and proposed interventions should best be based on a structured model grounded in (economic, physiological and/or other) theory and reflect for intermediate and final outputs and outcome established hypothesis based on prior work and measurement. Such a structured model on financial capability interventions is still missing and such an approach of measurement and evaluation with theory would allow also a much better use of the empirical results than narrow focus on a few treatment parameters under a social experiment approach proposed by the "randomnistas". Much has been said on the limitations of the latter". Two are stressed here: As hypothesis can never get verified, only falsified (Popper, 1935), a theory-less measurement approach requires a very high (essential infinite) number of experiments to gain confidence in the results. This is both impractical and wasteful. And the mere focus on the direct treatment effects provides little policy relevant information on policy design, reform and scaling-up unless substantiated by a broader assessment of the delivery mechanism and enabling environment. To stress, if you have a theory and some hypotheses beforehand as to what the channels of impact might be, you will have a better chance of designing an intervention that would help clarify the causal impacts. And, if you combine a welldesigned experiment with some mixed methods evaluation, you'd have a much better understanding of how you might have gotten from A to B.

Yet, to inform the development of hypotheses and fully structured model requires high-quality quantitative and qualitative evaluations that have been mostly absent so far. While the number of (financial education) interventions to improve financial literacy has increased dramatically, a rigorous monitoring and evaluation of such interventions is still the exception not the rule, particularly with regard to the measurement of impact. Impact evaluations, when done, are furthermore predominantly ex-post and not part and parcel of the overall intervention design which limits quality and value of results. There seem to be many reasons why M\&E is not included in intervention design ranging from lacking understanding by the program sponsor of their importance to the reluctance to provide substantial funds in addition to financing the intervention. Last but not least, if impact evaluations are undertaken at all they often focus on the quantitative impact and little on the qualitative process evaluation. The latter seems of particular importance to assess and distinguish effective and less effective ways of delivery.

\section{(iii)Financial Education, Behavioral Finance, and Alternatives to Impact Outcomes}

Much of the current attempts to increase financial literacy/capability have been and continue being focused on diverse methods of financial education albeit with limited empirical evidence that they are very effective, if at all. The results from the burgeoning literature on behavioral economics provides an explanation why education may have limited effects on improving financial capabilities; yet they provide also hints on how to improve behavioral outcomes. If

\footnotetext{
${ }^{4}$ For a discussion see Ravallion (2008 and 2009) who tirelessly hammers these important points inside and outside the World Bank. For integrating qualitative and quantitative approaches in program evaluations, see Rao and Wooolcock (2003).
} 
both were to largely fail, at least for critical groups, other measures would need to be explored and tested.

The limited empirical evidence does not lend strong support that financial education is effective, i.e. that it has documented and consistent positive impact on financial knowledge and/or behavior. Most international reviews of the sparse evidence come to similar conclusion as Akinson (2008, p. 5): "there is little in the way of robust evidence to show the overall effect of financial training" ${ }^{\prime 5}$. This conclusion is valid across different types of intervention from more academic training in schools to more ad-hoc training at the work place. They are also broadly echoed by the few evaluations in poorer countries mostly undertaken around microfinance projects. This lack of evidence is no proof that financial education never works and never will but to claim from a few significant coefficients of a few studies that it works is clearly wrong. This unsatisfactory situation may be due to a small size of available studies, inappropriately chosen results indicators, data and estimation issues, little attention to type and quality of the delivery mechanism, lack of control group, predominance of ex-post evaluations, etc. But this calls for caution and not pushing for more of the same until better evidence is at hand as well as the need for more and rigorous impact evaluations that are part and parcel of overall program design.

Of course, there is also the possibility that financial education may actually do very little for financial capability, at least for main aspects such as planning ahead. While good school-type financial education may be effective to increase financial knowledge and linked with hands-on training actually improve financial skills, there may be no impact on attitude even less on behavior. Attitude issues may be predominantly linked to lacking trust in financial institutions (in some countries) or encrusted cultural norms that may need interventions outside financial education to be addressed. And even if attitude issues can be overcome by financial education, and a desire to, say, plan their finances is instilled in consumers, there may be powerful other impediments to change behavior to follow through with the saving plan. The literature of behavioral finance provides many examples of cognitive biases with regard to attitude as well behavior such as procrastination, regret and loss aversion, mental accounting, status quo and informal overload ${ }^{6}$. This has let some authors to question the role of financial education to enhance financial capabilities and to claim that psychology not knowledge may be the main driver of what people actually do (e.g. Willis 2008, de Meza et al, 2008).

If this were to be broadly true, then the types of interventions to improve behavioral outcomes would need to be revised and those innovations could be guided by results of behavioral finance and the broader field of psychology. ${ }^{7}$ And partly this is already happening. For example, the lack of planning and following through for retirement saving has let to changing the default

\footnotetext{
${ }^{5}$ For other recent reviews on the effectiveness of financial education see Orton (2007), Atkinson (2008), Mundy (2009), O’Connell (2009).

${ }^{6}$ For a recent and excellent survey on psychology and economics, see DellaVigna (2009).

${ }^{7}$ For reviews and suggestions of how to use behavioral economics/economic psychology to make financial education more effective, see De Mello Ferreira (2010) and Yoong (2010).
} 
option in private (such as US) and public pension plans (New Zealand and soon UK) using inertia and the status quo bias to overcome behavioral shortcomings. Information overload that creates indecision can be addressed by reducing the number of options, such as the number of pension funds to choose from. More broadly, the design of the (financial) choice environment can be adjusted to "nudge" individuals toward desired behaviors while keeping their decision autonomy (Thaler and Sunstein, 2008). But also more direct approaches to change behavior are gaining importance. Social marketing for health issues (HIV-AIDS) and road safety (seat belts) is claimed to have been successful to change behavior without going through the knowledgebased cognitive route. There are out-of-date examples from some Central European countries that saving behavior was reportedly positively influenced by the then World Saving Day on October 31 every year, the related information campaign in schools, and the peer pressure to have your money pig full when you bring it to the school and then savings bank this very day. Current examples of an attempt to directly influence financial attitude and behavior are “edutainment” interventions with key messages on behavior delivered in TV soaps, TV clips, or street theatre ${ }^{8}$. To my knowledge so far none of them have been subject to rigorous impact evaluation but two are in preparation (TV soap in Kenya and radio soap in South Africa, both financed under the Financial Education Fund). Empirical knowledge for a broader set of interventions would be important to understand the binding constraints for behavior change and the trade-offs between the alternative interventions. If these interventions were to fail to improve desired behavior, at least for main sub-groups, this would call for other public policy interventions, including much more hands-on consumer protection.

Summing-up: The recent experience in high-income countries provides rich, albeit incomplete, material to guide the introduction of financial literacy policies and programs in low and middle income world. It provides critical leads and lessons on how to proceed, including the need for clear objectives, focus on measurement, and experimentation in interventions. But it needs adaptation for low-income communities in low- and middle-income countries.

\section{The Background for Financial Literacy in Low- and Middle Income Countries}

The last few years have also seen a rising interest in financial literacy issues in both low and middle income countries (LICs and MICs in World Bank terminology). This can be documented by the number of countries that have started financial literacy initiatives (see OECD Financial Gateway website), by the number of conferences and workshops held on the topics and the rising number of countries participating, and by specific initiatives of BRICS countries as well as regional initiatives for low-income countries. The latter includes the Partnership on Making Finance Work for Africa established in 2008 that includes a focus on financial capability, and the related September 2009 Accra conference that brought together over 200 participants from most

\footnotetext{
8 There are a few empirical studies that show an impact of TV soaps on behavior, such as fertility and divorces (see, e.g. Cong-Duryea-La Ferrara, 2008 and Chong and La Ferrara, 2008) but they do not qualify as measuring the impact of a purposeful message on behavioral outcomes.
} 
African countries on the issue of financial capability and consumer protection ${ }^{9}$. This rising interest in financial literacy in the less-affluent part of the world has many different motivations of which a 3 may stick out: Concerns with the perceived low level of financial capability; concerns with the low level of financial access or use; and the recognition that finance is a critical element for innovation and growth.

This section outlines common and idiosyncratic characteristics of LICs and MICs that will be important to consider when measuring the level of financial literacy and designing interventions how to raise it, starting out with a definition of those countries and their common relevant characteristics (compared to high income countries - HICs).

\section{(i) Definition of LICs and MICs and Common Relevant Characteristics}

The World Bank's definition of low and middle income countries is related to their access to financial services of the World Bank Group that is linked to income thresholds measured in gross national income (GNI) per capita. LICs are countries with GNI per capita below some US\$ 1,100 that makes them eligible for grants and subsidized loans under the International Development Agency - IDA (the soft lending arm of the World Bank Group). MICs are countries with a per capita GNI between US\$1,100 and slightly above US\$ 10,000 who can access loans under the terms of the International Bank for Reconstruction and Development IBRD (the market-based lending arm). While these limits are admittedly somewhat arbitrary they broadly reflect the financial needs and opportunities such as the access (or their lack of) to the international capital market.

LICs share a number of common characteristics that are relevant for the purpose of financial capability, its measurement, and the design of financial literacy policies and interventions. Five interrelated characteristics seem of particular relevance: Access, poverty, rural, informality, and risk management.

Access to financial services in LICs is very limited for a very large share of the population. If measured as the percent of households that have an account in a financial institution, the distribution of account use in Figure 1 matches very much the distribution between LICs, MICs and HICs. In most LICs account use is 20 percent and below while it is 80 percent above for HICs, with MICs somewhere in between. These figures are likely to overstate the account use by individuals as households are considered. From a measurement point of view it is difficult to differentiate financial capability from financial access or use as all are interrelated but not the same. In a high-income country there is rather less overlap between the people who are financially excluded (who tend to be small in number and concentrated among those on low incomes) and those with low levels of financial capability (who are more numerous and span all income levels). In a low-income country, where the majority of the population makes no use of formal financial services, the overlap is far greater and low financial capability (in terms of awareness of financial services provision) often constrains demand.

\footnotetext{
${ }^{9}$ See the web-site for further information: www.mfw4a.org
} 
Figure 1: Financial Access Map: Percent of Households with an Account in a Financial Institution

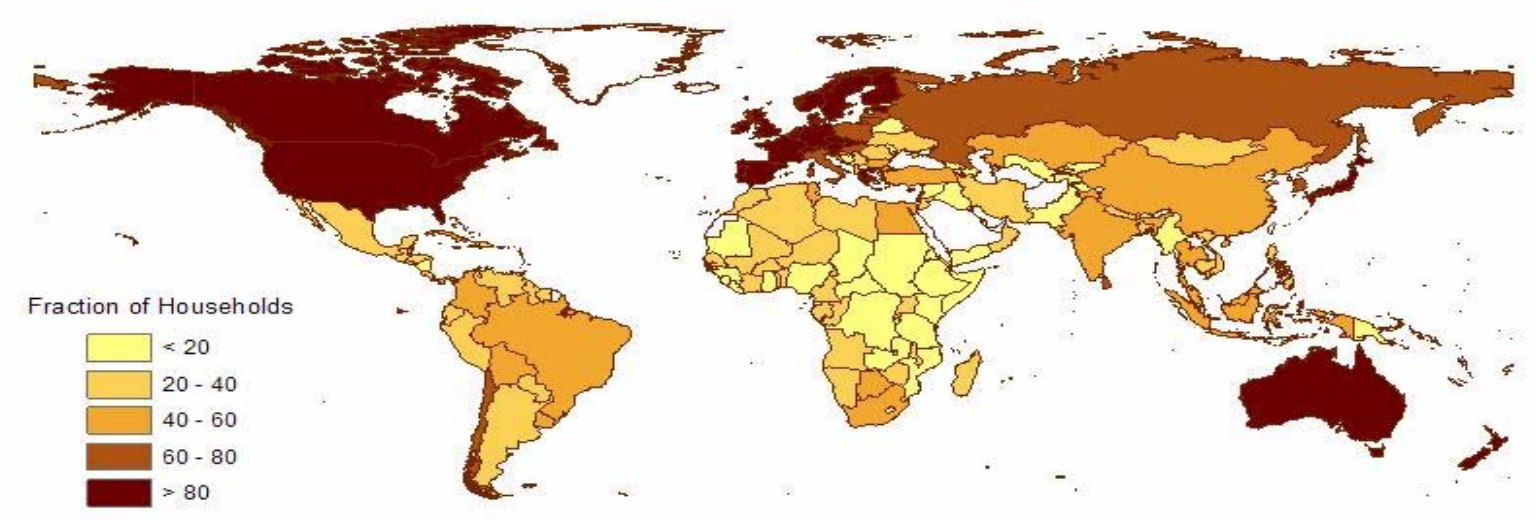

Source: World Bank (2008)

Poverty: LICs not only have a lower income per capita but mostly also a much larger share of poor in the population, whether measured as absolute poverty (e.g. those living on below 1 or 2 dollars a day) or as relative poverty (e.g. share of individuals having, say, less than 60 percent of the median income) as income inequality is typically also higher. Absolute poverty induces special behavior as physical survival takes priority. Such a behavior is often akin to that of lacking financial capability albeit the individual may behave differently if not poor.

Rural: Most of the population in LICs live in rural and often sparely populated areas with limited exposure to financial institutions and products; more limited cash needs; assets predominantly in land, cattle, seeds or gold; and living in larger families and tight knit communities. This creates special behavior for planning and saving that may be insufficiently appreciated if behavioral outcomes are assessed only in monetary terms.

Informality is the vastly dominant form of "employment" in LICs where formal employment (i.e. with labor contract or licensed, and paying social security contributions and income taxes) is restricted to very small share of the population (often 10 percent or less) and the large majority has the status of working on their own account. As a result managing money and other resources for large part of the population means managing jointly the accounts of a consumer and a microbusiness.

Risks: LICs are characterized by high level of natural, security, economic and other risks with limited access to formal (public and private) risk management instruments under in any case incomplete financial markets and limited social transfer programs. Their risk hit list is dominated by risks related to agricultural production and health that are managed by informal risk management arrangements (family, community). Hence, short-term weather and other 
insurances, where they exist, are of primary interest. As short-term risks dominate, long-term planning and saving, e.g. for retirement, is not a priority for most individuals. Hence such a behavior does not necessarily signal lacking financial capability or even myopia; it is rational ${ }^{10}$.

These characteristics are bound to influence the priorities of policy makers with regard to the objectives of financial literacy programs and the target groups, the way individuals behave "financially" and how they will react to interventions to change their behavior, and how financial capability can be measured. In addition, LICs exhibit other and more idiosyncratic characteristics that may differ in importance across countries and regions but are likely to influence measurement of financial capability and the working of capability improvement interventions (discussed below).

\section{Figure 2: Regional Variation of Percent of Households with an Account}

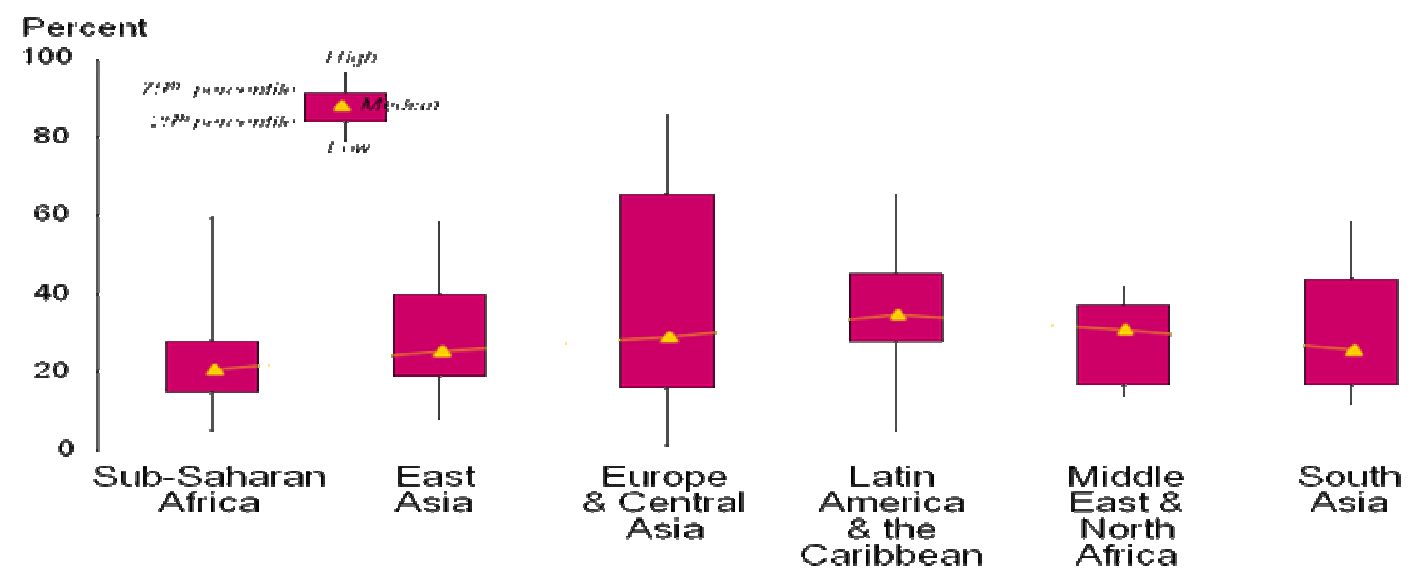

Source: Honohan (2006)

MICs can be described as countries that share the characteristics of both LICS and HICs, but exhibit higher heterogeneity. Hence part of the population in a MIC will exhibit characteristics and financial behavior as in an LIC, others will be much closer to HIC. An indication for such a mixed situation is given in Figure 2 that presents the regional variation of account holding between the 25 th and $75^{\text {th }}$ percentile. Such a variation is very small in Sub-Saharan Africa that consists essentially of LICs; it is much larger in the (World Bank) region of [Central and Eastern] Europe and Central Asia that consists mainly of MICs that are furthermore countries emerging from economic transition with specific issues of their own (such as low financial market development given their income level). This needs to be taken into account when measuring financial capability and designing interventions. Such issues exist to a more limited extent also in HIC with a presence of ethnic minorities and other subgroups.

\footnotetext{
${ }^{10}$ For a presentation of the Social Risk Management framework and its implication, see Holzmann and Jorgenson (2001).
} 


\section{(ii) Idiosyncratic characteristics that may matter}

Beside these common characteristics there are a number of more idiosyncratic characteristics that will influence the why and the what, for whom, and the how of financial literacy programs, in particular in LICs. The following list is not exhaustive but demonstrative.

Why and what: While policy statements on the objectives of financial literacy in LICs often mirror that of MICs and HICs (or have been copied from there) a common objective of financial literacy is to facilitate and increase access to financial services, if only the most basic one (i.e. bank account). Two other objectives have some commonality albeit with different emphasis in these countries: Basic business education and over-indebtedness.

Basic business education: As most individuals are own account workers, as mentioned above, their financial account management typically mixes money management of consumer and business with, at times, detrimental effects for both. Hence the frequent request of financial capability program to strengthen basic business education. However, how to define, measure, and separate this from the financial capability of this very consumer?

Over-indebtedness: A specific overriding concern in many but not all LICs is the level of debt of major subgroups of the population with formal and informal lenders. This indebtedness is linked, as in HICs, to low level of financial capability and poverty but may also reflect, at times, cultural issues that have been little explored.

Avoiding scams and unscrupulous providers: In some countries the regulation of financial services and consumer protection legislation is rudimentary and can put consumers at risk of scams and unscrupulous (if not criminal) providers of financial services. A poorly regulated formal financial services sector can also undermine consumer confidence in and use of their services.

For whom: As few national financial literacy (not capability) surveys have been undertaken in LICs (and MICs) the key target groups are not yet appropriately identified. What emerged from other surveys and studies is that gender may require a special focus and treatment in capability surveys as well as education and other intervention programs. In some regions and countries gender specific differentiation with regard to financial decision seems to take place that range from largely an exclusion of women from key budgeting and planning decisions to women largely running the business, day-to-day budget as well as precautionary saving budget.

How to do it: There are various indications that financial capability surveys and interventions in LICs will have to take account of country specificities both with regard to the content domain as well as the delivery mechanism. Here are a few examples:

Event specific interventions: In many countries remittances play a major role for household resources; this may affect the measurement financial capability as well as creating a teachable moment. Similarly, Conditional Cash Transfers are gaining importance on both LICs and MICs with similar challenges as well as opportunities. 
Financial access: Microfinance has gained importance in many LICs and MICs that may influence financial behavior and has been used already for financial education. Similarly, mobile phones are becoming a primary instrument to provide financial access, in particular to the very poor, and create opportunities for financial education.

Providers of financial education: The life in most LICs is still structured around a tight knit community and trusted persons. This is likely to influence financial decisions but can also be an opportunity to provide information as well as help change financial behavior.

Cultural differences: Last but not least some striking cultural norms may explain some of the differences in saving behavior (and measured differences in financial capabilities). For example, in many African societies till today is it difficult to keep liquid resources away from the demands of the extended family. There are good (historic) economic and anthropological explanations for such requests of sharing available resources (see, for example, Platteau, 1996). But it leads to low holding of liquid assets in cash or accounts and preferences for illiquid assets for medium and longer-term needs. This will impact the measured financial capability but financial education may do little to make this behavior go it away.

Summing-up: LICs and MICs exhibit numerous common and idiosyncratic characteristics that will influence financial behavior differently from HICs with a bearing on how to measure financial capability and on the effectiveness of financial education and alternative interventions.

\section{Developing Instruments to Measure Financial Capability and the Effectiveness of Interventions in LICs and MICs - The Work Program under the Trust Fund of the Russian Federation}

The prior two section served to motivate some of the thinking that is behind the work program under the World Bank administered Trust Fund (TF) on Financial Literacy and Education sponsored by the Russian Federation. The origins of the TF are linked to the Russian G8 presidency of 2006 in which financial literacy and education was introduced as an important topic in the Pre-Summit Statement by the G8 Ministers of Finance (St. Petersburg, June 9-10, 2006) ${ }^{11}$ and the events included an OECD-organized conference on the topic in Moscow in December 2006 with broad international participation. The topic is close to the domestic policy agenda of Russia as financial literacy of the population is considered much too low but crucial for its economic development. A Russia-World Bank project on financial literacy and education is under preparation and will start later in 2010.

\footnotetext{
11 “ 6 . We acknowledge the importance of better financial education and literacy for improving the ability of people to use financial services and to make effective decisions with respect to their present and future welfare. We welcome the ongoing work in the OECD on the Financial Education Project and call for further development of financial literacy guidelines based on best practices...We call on the IFIs and other donors to support best practices in financial access programs and to improve coverage, accuracy and comparability of data on financial access and financial sector performance. We encourage efforts at the country level to remove obstacles preventing access to financial services, including lowering the costs of remittances.”
} 
Discussions with Russian government officials during the Moscow conference led to the idea and proposal for a TF that should assist in the implementation of the Summit Statement; the TF was established in October 2008. The TF will finance joint and individual work programs of OECD and World Bank with a total amount of \$ 15 million over 3 years and cover 6 main activities: (1) The Review of Current Status of Financial Literacy and Financial Education Programs to inform the Development of Methodologies for Measurement and Evaluation; (2) Development of Standard Methodologies for the Assessment of Financial Literacy, Knowledge and Skills and the Measurement of the Impact and Outcomes of Education Programs; (3) Development of Standards, Criteria and Guidelines for Financial Literacy Improvement Programs and the Design and Operation of Outreach and Education Programs; (4) Testing and Evaluating the Measurement of Financial Literacy and Effectiveness of Education Programs; (5) Capacity Building (in LICs and MICs); (6) and Knowledge Dissemination. Altogether, the results of the work program should enable LICs and MICs to develop better informed national strategies on financial literacy and education. Financing such trust-funded work for the benefit of developing countries is in line with the move of Russia from a World Bank client to a donor country and her stronger engagement in development policy.

This Section will focus on and outline 2 key activities of the World Bank-led work program under implementation, namely (i) the development of methodologies and an operational instrument to measure financial capability in LICs and MICs that makes the results comparable across time and space, and (ii) the development of methodologies and operational instruments to better assess the effectiveness of financial education and other interventions to improve financial capability ${ }^{12}$. The preparation of this work program was guided by two workshops - a prepworkshop with a small group of experts in January 2009 in Vienna and a larger workshop in November 2009 in Washington, DC for which a broad spectrum of experts across different fields and countries were invited.

\section{(i) Assessing Financial Capability in Low and Middle Income Countries}

The ultimate objective of this work program is to provide a (free) operational instrument (or toolkit) for LICs and MICs that has been country-tested to allow them to implement national capability surveys that deliver results which are comparable across time and space. To this end, the critical initial question for the development of such a tested methodology was if it should start anew or rely on existing approaches. The discussion in the prior sections suggests that LICs and MICS have many specific characteristics so that a direct application of an existing survey methodology that was developed for HICs may not lead to the best results. While existing

\footnotetext{
${ }^{12}$ This work program is developed und undertaken under my conceptual leadership with Richard Hinz as the World Bank task team leader and TF responsible, a team of Bank staff (Mattias Lundberg, Florentina Mulaj, Valeria Perotti, Kinnon Scott) and members of an Expert Advisory Group, and with Prof. Elaine Kempson in the role of lead consultant for both the survey as well as the M\&E work program. All are working under the overall guidance by the World Bank TF Steering Committee. Much of the toolkit developments and country work will be outsourced through competitive pilots.
} 
surveys for LICs and MICs (e.g. for Kenya and Russia) provide interesting leads they do not offer a fully developed methodology to build on. But building from scratch a new approach is resource and time intensive and the resources so spent limit the number of country pilots for a comprehensive testing. On the other hand the FSA methodology applied in the UK and a few other countries proposes content domains that are having universal appeal while being open to adjustments in domains, questions and coding. For this reason is was decided to use the FSA approach as the starting point and think about a process how best to adjust it to the circumstances of LICs and MICs. If feasible, the changes should be such that the resulting financial capability scores in the identified content domains are comparable with HICs.

The process for this adjustment and testing is conceptualized in two stages: Stage 1 explores the domains, questions and coding in 6 plus country pilots. This should result in a common draft survey methodology that is applied in Stage 2 in the same and possibly other countries. In a final $3^{\text {rd }}$ Stage the results and lessons from both stages are then translated into the operational instrument, published and become available as public good.

Stage 1: Exploring domains, questions and coding in at least 6 country pilots. Under the process for Stage 1 interested country teams apply (through a World Bank Task Team Leader) to participate in the pilots ${ }^{13}$. In return the country team receives co-financing for the development work as well as full technical support by the TF team (including the Expert Advisory Group). The country selection is done by the quality of proposal and research team, and strives for a diversification across income levels and regions. 16 applications covering 18 countries were received of which 6 applications covering 8 countries (of which 3 low-income) from 3 regions (Latin America, Sub-Saharan Africa, and East Asia) were selected.

The selected country teams are invited to a first workshop that guides the implementation of at least 6 focus groups in each country (with people of different ages, occupations, locations, etc). The work of the focus groups should help identify or validate the critical content domains of what constitutes financial capability in a low and middle income environment with focus on lowincome groups differentiated by ages, location, occupation, etc. Some of the selected country teams have already undertaken preparatory work on questionnaires based on the FSA approach, others have used related but different approaches (e.g. based on FinScope ${ }^{14}$ ). This should allow for mutual learning. The goal is to arrive at a common framework while allowing for some country-specific deviations.

The results of the focus groups are then presented by each country at a second workshop and compared across countries. The result will help the preparation of guidelines for the following at least 30 in-depth interviews in each country. These interviews should develop appropriate

\footnotetext{
${ }^{13}$ For more details on the TOR, see http://go.worldbank.org/8XW9MOO7G0

${ }^{14}$ FinScope, a FinMark Trust initiative for Sub-Saharan Africa, is a nationally representative study of consumers' perceptions on financial services and issues, which creates insight to how consumers source their income and manage their financial lives; see www.finscope.co.za.
} 
survey questions. Again the TF team with members of the expert advisory group will participate and assist the country teams.

The results of the in-depth interviews are presented by the pilot countries at the third and final workshop of Stage 1. These results, comparison across countries, and the support by the TF team will inform the development of core questionnaire modules to be used for surveys at Stage 2. The three workshops with the selected countries are scheduled from September 2010 to early 2011.

Stage 2: Implementing the draft survey in 6 plus pilot countries

For the implementation of the draft survey both countries that participated in stage 1 and, perhaps, other new pilot countries can apply. It is anticipated that there will be an open window for funding for Stage 2 in late 2010 or early 2011. In return each selected country receives cofinancing of the survey implementation as well as full technical support by the World Bank team (including an external Expert Advisory Group) for survey preparation, scoring work and results presentation.

The survey implementation may be done through stand alone national surveys or through modules that are attached to a larger existing survey providing that the survey methods are consistent with the framework and guidelines developed by the TF team. Surveys to be financed in Stage 2 should cover a nationally representative sample of the adult population contacted through face-to-face interviews and measure financial capability following the framework developed in Stage 1. Surveys should also collect information on basic demographics, economic activity status, current income and wealth of the respondents, and adopt a random sampling strategy. The survey questionnaire needs to include the modules developed as a result of Stage 1, but may include additional topics as required by specific needs in each country.

When the survey data has been collected, experts from the country teams that have collected the data will work with the World Bank expert group to develop a common method of scoring the replies. Country teams are required to provide the World Bank with a detailed report giving the results from the surveys conducted in Stage 2. Guidelines on the format of this report will be developed with the Trust Fund team. In addition, applicants are required to supply digital files (in STATA/SPSS format if possible, or in open-source format otherwise) containing anonymized microdata collected in the interviews.

\section{Stage 3: Producing the operational survey instrument}

The results and lessons from both stages are then translated by the TF team into the operational instrument. To guide this production an international workshops is planned for late 2011 where the country results are discussed and, perhaps, made fully available on the TF website (under completion). Once finalized and published it should become available on the web as a toolkit (and public good). 


\section{(ii) Assessing the Effectiveness of Financial Education and similar Interventions}

This part of the work program aims to address key impediments that have characterized the evaluation of financial education programs so far, in particular the low interest by financial education providers in rigorous $M \& E$ and the non-comparability of evaluation results even when undertaken. To this end the work program consists of 3 interrelated components: The development of an impact evaluation toolkit for financial education and related interventions; financial support of impact evaluations for country-specific intervention projects; and financing integrated impact evaluations of financial education projects. The ultimate objective is to develop an operational impact evaluation framework with a common results framework, a toolkit for quantitative and qualitative impact evaluation methods, and operational guidelines that can be used to assess the impact of financial education programs and related interventions in LICs and MICs.

\section{The development of an M\&E toolkit for financial education and related interventions}

Most financial education providers are little aware of the benefits of a rigorous impact evaluation and the list includes government agencies, NGOs, and financial market institutions. Even when they have some sense of the benefits they are often not willing to spend the resources in view of perceived low direct benefits and high externalities. And even if they wanted to spend the resources they cannot turn to a toolkit that outlines the process and options of impact evaluation in an accessible manner. While by now various generic introductions to and toolkits for impact evaluation do exist they do not relate to financial education programs and hence have limited

appeal to financial education providers. ${ }^{15}$ Having a dedicated toolkit should motivate and empower financial education providers to include rigorous impact evaluation considerations already in the design phase and allow an informed and productive interaction with impact evaluators (from private sector and academia).

To make the toolkit as relevant and operational as possible it will be developed in interaction with the initial round of sponsored country impact evaluations. This interaction should assure a

\footnotetext{
${ }^{15}$ For example Pitman, Feinstein and Ingram (2005), Imas and Rist (2009), Khandker, Koolwal, and Samad (2009). Key online resources include:

MIT Poverty Action Lab: http://www.povertyactionlab.org/

Monitoring \& Evaluation News: http://www.mande.co.uk

World Bank - Spanish Trust Fund for Impact Evaluation and Results-based Management in HD sectors: http://web.worldbank.org/WBSITE/EXTERNAL/EXTABOUTUS/ORGANIZATION/EXTHDNETWORK/EXTHDOFFICE/0,"C ontentMDK:22383030 menuPK:6508083 pagePK:64168445 piPK:64168309 theSitePK:5485727,00.html World Bank - Monitoring \& Evaluation Capacity Development: http://www.worldbank.org/oed/ecd World Bank- The Development Impact Evaluation (DIME) Initiative: http://web.worldbank.org/WBSITE/EXTERNAL/EXTDEC/EXTDEVIMPEVAINI/0, menuPK:3998281 pagePK:64168427 〜piPK:64168435 theSitePK:3998212,00.html
} 
mutual learning process as the developers of the toolkit together with the TF team are expected to support the sponsored interventions with expert advice.

The Expression of Interested (EOI) for the development of the impact evaluation toolkit has been posted with deadline of July $24^{16}$, and the selected best 3 expressions will be invited to provide a more comprehensive proposal for this toolkit by end-August 2010.

\section{Financial support of impact evaluations of country-specific intervention projects}

Financial support for rigorous impact evaluation should help to overcome the traditional resistance by financial education providers to spend money on this and also allow the TF to influence the selection of the evaluated topics and delivery mechanism. There will be two phases for such support.

During the initial phase the support consists in financing the impact evaluations as well as providing expert advice through the TF team (including members of the Expert Advisor Group) and the producers of the M\&E toolkit. Such a support in the initial phase is of particular importance for the development of a fully fledged results framework.

Depending on available resources, a new call for proposals is planned to be issued to solicit additional evaluation proposals in early 2011 after the draft toolkit has been developed. Key criteria for successful solicitation will then be to apply the toolkit in the implementation of the impact evaluation.

In order to align the supported impact evaluation with the (adjusted) capability concept, the perceived capability gaps, and the learning about effectiveness of alternative delivery mechanisms, all geared toward the target groups, the selection criteria for the initial phase include: ${ }^{17}$

\section{$\underline{\text { Areas of Focus }}$}

Topics:

- Day-to-day financial management (personal finance)

- Planning for the long-term (budgeting, savings, investments, retirement, education planning)

- Planning for the unexpected (budgeting, savings, insurance)

Target groups:

- Low-income consumers in low and middle income countries: school children, people working in the informal economy, farm households, micro-enterprise owners, recipients of government-to-people transfers.

\footnotetext{
${ }^{16}$ For more details on the EOI, see https://wbgeconsult2.worldbank.org/wbgec/index.html

${ }^{17}$ For more details on the TOR, see http://go.worldbank.org/8XW9MOO7G0
} 
Delivery mechanisms:

- Formal financial education (one-to-one and classroom based): targeting school children, people working in informal economy, or generally low-income consumers.

- Social marketing/edutainment: targeting people working in informal economy, generally low-income consumers, including opportunities created by significant life events, such as birth of a new child, death in family, health related problems, etc.

- Financial education for micro-enterprise: targeting people working in informal economy, farm households, or other subgroups representing low-income population.

- Opportunities provided by government-to-people transfers:

o Conditional cash transfers (CCTs)

0 Matching defined contributions (MDC) savings arrangements, and

o Other government-to-people transfers

\section{Scope of Programs}

In order to lend better for findings from the funded pilots to be generalized, all projects are expected to:

- measure the effect of financial education programs on knowledge enhancement;

- measure the effect of financial education programs on changing behavior; and

- measure the extent to which the change in behavior improves decision making and enhances the financial well-being of consumers.

\section{$\underline{\text { Results Framework }}$}

Each project proposal considered for selection and financing needs to plan for a comprehensive results framework, with clearly defined objectives of the intervention and fully developed results chain from the proposed delivery mechanism to the expected outputs, outcomes and impact, with proposed indicators.

Evaluation Methods

The purpose of the evaluation is to make an assessment of both the delivery mechanisms as well as of the objectives, outcomes and impacts of financial education programs and other promising interventions such as edutainment, social marketing and one-to-one counseling. Therefore, a combination of process evaluation and impact evaluation is expected, including qualitative research methods (in-depth interviews, focus groups, or observation techniques) and quantitative experimental studies.

Each study must determine both causality and attribution. It must be able to show to the most rigorous extent possible whether or not the observed outcomes were likely to have been caused by the intervention being evaluated, and it must be able to control for or otherwise dismiss other possible explanations for the observed outcomes. In addition, the study must strive for external validity. The evaluation must be able to control for unobserved factors that might determine heterogeneity in outcomes. These criteria are conventionally satisfied by the use of experiments 
with random assignment of treatment and control or comparison groups, but other methods for identifying a counterfactual will be welcomed, especially in the cases where treatment is not easily excludable. In addition, proposals are welcome to test one (or more) method(s) with alternative audience/recipient groups and/or alternative methods of delivery, and examine doseresponse effects. The Trust Fund is also interested to study how much financial education is optimal, and whether differences in pedagogy or content matter.

The proposal must clearly describe the identification strategy to be used. In addition the proposal must include information on the population and sample to be studied, including size and power calculations, expected effect sizes, and how the study will deal with departures from probability sampling and issues such as non-random attrition.

For the initial phase of the M\&E work 14 countries applied of which 4 countries in 3 regions (Latin America, Sub-Saharan Africa and South Asia) were selected. A key criterion for the selection was the learning aspect of the intervention and the information for the development of the toolkit.

\section{Financing integrated impact evaluation of financial education projects}

The currently available impact evaluations of financial education and alternative interventions are little comparable as they use different input, intermediate or final outcome indicators for their estimations disallowing the generalization of impact or interference about the relative effectiveness of interventions. In order to do so, ideally the effectiveness of a set of alternative interventions should be evaluated under comparable conditions simultaneously in a variety of countries. As a first step in this direction the TF is sponsoring the evaluation of different interventions in individual countries (e.g. three variants of financial literacy programs) and the same intervention in different countries (e.g. remittances-focused financial literacy program). This work is led by a team of the Bank's research group DEC. Pending financial resources such a research window may be opened later in 2010 for international competitive application.

\section{Dissemination}

The intermediate results (such as the draft M\&E toolkit) and final results will be presented at international workshops and conferences in 2011 and 2012. To this end we plan to link-up with similar exercises under implementation by the DFID-financed Financial Education Fund that finances both financial education interventions as well as their impact evaluation. ${ }^{18}$

\footnotetext{
${ }^{18}$ This DFID financed program provides financial resources for interventions and M\&E on financial education in Sub-Saharan Africa to the tune of pounds 3.2 million. 9 programs have been selected in the first round (starting in late 2009) and 6 in a second round (starting as of June 1, 2010). See www.financialeducationfund.org
} 


\section{Summing-up and Conclusions}

This paper presents a World Bank-led work program that is financed under a trust fund by the Russian Federation. This program together with other activities, partly led by the OECD, aims at supporting the development of effective financial literacy and education strategies and programs in low and middle income countries. The selection of two activities and their staging have been motivated by the experiences and lessons of high-income countries with such programs and the deviating characteristics of low and middle income countries.

High income countries have experienced strong interest in and activities on financial literacy and education during the last decade that provide a rich albeit incomplete material to guide financial literacy and education activities in low and middle income world. Main progress been made to move from a knowledge-based concept of financial literacy to a behavior-based concept of financial capability. Yet the evidence that financial education matters to improve financial literacy even less capability is limited and not robust, and based on few rigorous evaluations. Furthermore, such a result would be consistent with the lessons from behavioral finance which suggest that psychology not education matter for financial behavior. This calls for more testing, including of alternative interventions such as "edutainment".

Low and middle income countries exhibit many common and a few idiosyncratic characteristics that suggest that a mere transfer of concepts how to measure financial literacy/capability and how to improve it may not lead to the best result. The common characteristics for low-income countries include low access to finance, high poverty, rural population, high informality, and special risk' profiles. Idiosyncratic characteristics include gender issues or cultural norms that differ across countries. Middle income countries have characteristics from both the rich and poor countries for different parts of the population. This calls for adjustments in the way capability is defined and measured, and how financial education and alternative interventions are provided.

Against this background two activities have been selected: (i) the development of an operational instrument to measure financial capability in low and middle income countries across time and space. It takes as starting point the capability approach developed by the UK Financial Service Authority but adjusted through a bottom-up multistage country pilots approach providing competitive grants and expert advice to the participating countries; and (ii) the development of an operational evaluation framework including results frame, evaluation toolkit and guidelines to help assess the impact of financial education programs and alternative interventions. Competitive grants are provided to finance the impact evaluation of financial education and other interventions which fulfill criteria with regard to topics, delivery mechanism or results framework.

The result of the TF activities should importantly improve the understanding of the working of financial literacy and education in low and middle income countries and assist in design and 
implementation of effective national strategies and programs. As this is a multi-year work program in progress, the interactions with the international research community will be crucial to participate in the work and to provide feedback and guidance.

\section{References}

Atkinson, Adele. 2008. Evidence of Impact: An Overview of Financial Education Evaluations. Consumer Research No. 68. FSA: London.

Atkinson, Adele. 2008. Measuring and Improving Financial Capability: Designing an approach for Kenya. Personal Finance Research Center, University of Bristol, October.

Beck, Thorsten, Aslı Demirgüç-Kunt and Patrick Honohan. 2009. "Access to Financial Services: Measurement, Impact and Policies.” World Bank Research Observer 24: 119-145.

Chong, Alberto, Suzanne Duryea, and Eliana La Ferrara. 2008. "Soap Operas and Fertility: Evidence from Brazil," CEPR Discussion Papers 6785. London: Centre for Economic Policy Research.

Chong, Alberto and Eliana La Ferrara, 2009. "Television and Divorce: Evidence from Brazilian Novelas," Journal of the European Economic Association 7(2-3): 458-468

DellaVigna, Stefano. Psychology and Economics: Evidence from the Field. Journal of Economic Literature 47 (2): 315-372.

De Mello Ferreira, Vera Rita. 2010. Financial Education - Can Economic Psychology and Behavioral Economics Help Improve it? Paper presented at the OECD-Bank of Italy Symposium on Financial Literacy: Improving Financial Education Efficiency, 9. June 2010, Rome.

De Meza, David, Bernd Irlenbush and Diane Reyniers. 2008. Financial Capability: A Behavioural Economics Perspective. Consumer Research No. 69. FSA: London.

Financial Service Authority (FSA). 2005. Measuring Financial Capability: An Exploratory Study. Consumer Research Study No. 37. FSA: London. . 2006a. Financial Capability in the UK: Establishing a Baseline. FSA: London. . 2006b. Financial Capability Baseline Survey: Methodological Report. Consumer Research Study No. 47a. FSA: London.

- 2006c. Financial Capability Baseline Survey: Questionnaire. Consumer Research Study No. 47b. FSA: London.

Holzmann, Robert and Steen Jorgensen. 2001. Social Risk Management: A new conceptual framework for social protection, and beyond. International Tax and Public Finance 8 (4): 529556. 
Honohan, Patrick. 2008. "Cross-Country Variation in Household Access to Financial Services.” Journal of Banking and Finance 32(11): 2493-2500.

Imas, Linda and Ray Rist. 2009. The Road to Results: Designing and Conducting Effective Development Evaluations. Washington, DC: The World Bank.

Khandker, S. R.; Koolwal, G. B. and H. Samad, 2009. Handbook on Quantitative Methods of Program Evaluation. Washington DC: The World Bank.

Kempson, Elaine. 2008. Financial Education Fund: Monitoring and Evaluation Policy and Procedures. Financial Education Inception Report. Mimeo, November.

Kempson, Elaine and Adele Atkinson. 2009. Measuring Levels of Financial Literacy at an International Level. OECD: Paris. Mimeo.

Microfinance Opportunities. 2006. Assessing the Outcomes of Financial Education Working Paper \#3. Available at: www.microfinanceopportunities.org

. 2009. Can Financial Education Change Behavior? Lessons from Bolivia and Sri Lanka. Working Paper \#4. December. Available at: www.microfinanceopportunities.org

Mundy, Shaun. 209. Financial Education Programmes in Schools: Analysis of Selected Current Programmes and Literature - Draft recommendations for best practices. OECD. Mimeo.

OECD. 2005. Improving Financial Literacy: Analysis of Issues and Policies. OECD: Paris.

OECD. 2009. Progress of the Work of the Expert Subgroup on the Evaluation of Financial Education Programs - Consultant Analytical Note: A Framework for the Evaluation of Financial Education Programs. OECD Network on Financial Education. Paris: OECD. October. Mimeo.

Orton Larry. 2007. Financial Literacy: Lessons from International Experience. Canadian Policy Research Network - CPRN Research Report. September.

O’Connell, Alison. 2009. Evaluating the Effectiveness of Financial Education Programmes. OECD: Paris. Mimeo.

Platteau, J.-P. (1996). "Mutual Insurance as an Elusive Concept in Traditional Rural Societies.” Journal of Development Studies 23(4), 461-490.

Pitman George, Osvaldo Feinstein, and Gregory Ingram. 2005, eds. Evaluating Development Effectiveness. New Brunswick, NJ: Transaction.

Popper, Karl. 1935. Die Logik der Forschung. Wien. [The Logic of Scientific Discovery. Routledge Classics, 1968]

Ravallion, Martin. 2008. Evaluation in the Practice of Development. Policy Research Work Paper 4547. World Bank: Washington, DC, December.

. 2009. Should the Randomistas Rule? The Berkeley Electronic Pres - Economists

Voice. www.bepress.com/cgi/viewcontent.cgi?article $=1368 \&$ context $=$ ev 
Rao, Vijayandra and Michael Woolkock. 2003. "Integrating Qualitative and Quantitative Approaches in Program Evaluation,” in Francois Bourguignon and Luiz Pereira da Silva (eds.) The Impact of Economic Policies on Poverty and Income Distribution: Evaluation Techniques and Tools. New York: Oxford University Press, pp. 165-90.

Thaler, Richard and Cass Sunstein, 2008. Nudge: Improving Decisions about Health, Wealth and Happiness. New Haven: Yale University Press.

Yoong, Joanne. 2010. Making Financial Education more Effective: Lessons from Behavioral Economics. Paper presented at the OECD-Bank of Italy Symposium on Financial Literacy: Improving Financial Education Efficiency, 9. June 2010, Rome.

Willis, Lauren E. 2008. Against Financial Literacy Education. Iowa Law Review 94.

World Bank. 2008. Finance for All? Policies and Pitfalls in Expanding Access. A World Bank Policy Research Report. World Bank: Washington, DC. 